\title{
ESPETÁCULO "B.O. (BOLETIM DE OCORRÊNCIA)": \\ O TEMA DA VIOLÊNCIA ENTRE A REALIDADE E A FICÇÃO
}

OLIVEIRA, Mariana ${ }^{1}$

\section{RESUMO}

Este artigo apresenta e analisa um projeto teatral realizado em $2013 \mathrm{com}$ alunos do primeiro ano do Ensino Médio do CAp-UERJ, no âmbito da disciplina de Teatro. O projeto culminou com a apresentação do espetáculo "B.O. (Boletim de Ocorrência)", construído a partir de relatos fornecidos por diferentes pessoas da comunidade escolar entre os quais se constatou a presença de aspectos violentos. A reflexão aqui exposta busca compreender esse achado, considerando os campos da realidade e da ficção, além de esmiuçar e pensar acerca de cada etapa de nossa experiência teatral.

PaLAVRas-Chave: Teatro na escola - Realidade e ficção - Experiência.

\section{ABSTRACT}

This article presents and analyzes a theatrical project carried out in CAp-UERJ during the school year of 2013 within the scope of Theatre course, alongside students of the first year of High School. It had as its peak the presentation of "B.O. (Boletim de Ocorrência)" ("Police Report"), a show that was built upon accounts by a variety of members of the school community in which the presence of aspects of violence have been noticed. The reflection herein seeks to understand this phenomenon taking into consideration the fields of reality and fiction. Furthermore, we also expect to draw close attention to each step of our theatrical experience.

KEYWORDS: Theatre in school - Reality and fiction - Experience.

\footnotetext{
1 Professora Adjunta de Teatro do Instituto de Aplicação Fernando Rodrigues da Silveira (CAp-UERJ). Email: marioladasmontanhas@gmail.com
} 


\section{REGISTRO DA OCORRÊNCIA}

Circunscrição: disciplina de Teatro

Responsável: professora Mariana Oliveira

\section{OCORRÊNCIA}

Apresentação do espetáculo "B.O. (Boletim de Ocorrência)"

Data do fato: 09 e 14 de dezembro de 2013

\section{Local: auditório do CAp-UERJ}

\section{ENVOLVIDOS}

20 alunos do $1^{\circ}$ ano E.M.

\section{DINÂMICA DO FATO}

O público entra e se acomoda. Black out. Projeção de vídeo (colagem de cenas violentas extraídas de clássicos do cinema: tiros, facadas, lutas, desastres automobilísticos). Música tensa. Tela preta. Projeção, em letras brancas, do título do espetáculo: "B.O. (Boletim de Ocorrência)". Black out novamente.

Esses eram, resumidamente, os momentos iniciais de um espetáculo teatral composto por oito cenas curtas, que traziam relatos marcados por diferentes tipos de violência: verbal, moral e até mesmo física. Nessas cenas, vinte alunosatores narravam, de maneira teatralizada, acontecimentos que não pertenciam às suas vidas. As histórias haviam sido extraídas de depoimentos fornecidos por algumas pessoas da comunidade escolar que haviam aceitado participar de nosso projeto.

\section{O PROJETO}

As primeiras aulas do curso de Teatro para os alunos do primeiro ano E.M. de 2013 fizeram convergir os interesses para a questão da personagem. Como uma contribuição para essa pesquisa, assistimos a trechos do filme "Jogo de cena", de Eduardo Coutinho (2007), em que diversas mulheres dão depoimentos sobre vivências emocionalmente marcantes. Entre essas mulheres, encontram-se, sem que $o$ filme as discrimine, aquelas que realmente viveram os acontecimentos relatados (ao menos supostamente) e atrizes que, tomando as primeiras como personagens, interpretam os mesmos relatos.

O filme nos confunde em diversos momentos sobre quem seria a verdadeira "autora" da história que está sendo contada. A montagem contribui para isso, já que, muitas vezes, vemos primeiro a atriz contar a história e, somente depois, a muIher que realmente a viveu. Além disso, entre as atrizes, há algumas muito conhecidas e outras não. No caso dessas últimas, parece impossível identificá-las. Ou seja, em momentos diferentes, vemos duas mulheres contando a mesma história, mas não sabemos qual delas realmente a viveu. E mesmo no caso das atrizes célebres, tal é o poder de suas interpretações, que por vezes nos perguntamos se partes dos relatos não pertenceriam, de fato, às suas próprias vidas.

E, assim, chegamos a algumas das questões que 0 filme pretende lançar. Primeiro, percebemos que o nosso discurso na vida real não é completamente espontâneo e verdadeiro, mas, em certa medida, construído. Refletimos também sobre o fato de que, muitas vezes, a ficção pode ser mais crível que a realidade: a dose "certa" de emoção ao se dizer uma coisa torna o discurso mais convincente ou, no mínimo, mais envolvente e interessante. Imaginamos quanto da vivência real das atrizes, ou sua "memória afetiva", para usar o termo do mestre teatral russo Constantin Stanislavski (1995), serve como componente de construção de suas personagens e ajuda a tecer a ilusão de realidade em suas atuações. Enfim, 0 atrito entre verdade e ficção que nos é exposto a todo o momento pelo jogo de cena criado por Coutinho faz surgirem questio- 
e-Mosaicos - Revista Multidisciplinar de Ensino, Pesquisa, Extensão e Cultura do Instituto de Aplicação Fernando Rodrigues da Silveira (CAp-UERJ)

namentos infinitos acerca da arte da interpretação e também dos gestos e comportamentos que, no jogo social, constroem nossas personas.

Fascinados pelo filme, seguimos, em nosso curso de Teatro, um procedimento de trabalho inspirado naquele adotado por Coutinho para a criação de sua obra. O cineasta havia publicado um anúncio de jornal convidando a participar de um teste para um filme documentário mulheres que, com mais de 18 anos, tivessem histórias para contar. Esse convite aparece no início do filme "Jogo de cena" e nos leva a imaginar que foi desta forma que o diretor encontrou e selecionou algumas das participantes de sua obra, as verdadeiras "autoras" dos relatos que a compõem. A partir disso, e no intuito de construir um espetáculo teatral, nós também saímos em busca de histórias alheias: cada aluno recebeu a tarefa de escolher e abordar uma pessoa da comunidade escolar para pedir-lhe que contasse uma história marcante de sua vida. Ao longo de uma semana, a turma trabalhou nisso e, na aula seguinte, trouxe resumos das histórias que havia colhido. Sentamo-nos em roda e pusemo-nos a escutá-los. Tratavam de acontecimentos diversos, mas ao fim percebemos, entre eles, a surpreendente recorrência de uma característica: a presença de traços violentos.

\section{Primeira etapa do trabalho: OS Rela- TOS DE VIOLÊNCIA}

Um aluno que, contrariado por não poder acompanhar seu irmão à enfermaria da escola, xinga a inspetora que o impede de fazer o que deseja. Um rapaz que, em seu primeiro emprego numa papelaria, é acusado injustamente de roubo e demitido de forma sumária e sem qualquer polidez. Um estudante que dorme no ônibus e, ao acordar num lugar desconhecido, é abordado por alguém que ele pensa ser um assaltante. Uma família que, em plena viagem de férias, de carro na estrada, é perseguida por ladrões. Adolescentes que, na praia de Ipanema durante o carnaval, brigam com um rapaz que tenta roubarIhes o gelo do isopor. Uma grávida que, ao sair de uma feira de gestantes com suas compras, é surpreendida por um tiroteio no estacionamento. Um segurança que, durante a tentativa de evitar um assalto, testemunha a morte de seu parceiro de trabalho.

Todas essas histórias foram colhidas pelos alunos junto a outros alunos, professores e inspetores da escola. À medida que íamos escutando esses relatos, íamos percebendo a incômoda recorrência de diferentes tipos de violência: a inspetora agredida verbalmente pelo aluno; 0 jovem trabalhador atacado moralmente em seu ambiente de trabalho; a tensão urbana e o imaginário da sempre iminente violência traduzida no temor do tipo de abordagem que um desconhecido pode nos fazer; a fuga de uma família, acossada por ladrões; o embate físico e cru entre jovens numa praia da zona sul do Rio de Janeiro; o risco que sofre a grávida em meio a um tiroteio, numa imagem de total contraste entre a delicada promessa de vida renovada e a brutalidade que atravessa os homens em nosso mundo; e, finalmente, a própria morte como decorrência de uma violenta disputa com armas de fogo.

Tal recorrência parecia, e ainda parece, instigante: é claro que são histórias que notoriamente fazem parte da realidade do mundo, mas por que razão essa concentração de traços violentos apareceu nos relatos de nossos entrevistados? Mais precisamente, qual seria o significado dessa recorrência? A explicação estaria na própria realidade brasileira? Ou deveríamos tentar compreendê-la a partir das relações entre violência, drama e ficção? Vejamos: 
1. A primeira hipótese para explicar a recorrência da violência nos relatos de nossos entrevistados supõe um aspecto documental que refletiria a sociedade violenta em que vivemos: violência como atos violentos propriamente ditos, quantificáveis em índices/estatísticas de violência (homicídios, assaltos, etc.) ou conhecidos por outros meios (repressão policial, tortura, etc.) e violência simbólica, marcada na estrutura social e cultural brasileira, em certa medida causadora do primeiro tipo. Neste caso, o resultado encontrado corroboraria a negação do mito de Brasil pacífico e dado essencialmente à cordialidade, no sentido disseminado pelo senso comum, isto é, como expressão de carinho, afeto e amizade.

2. A segunda hipótese desenvolve-se sob outro viés: teria a recorrência de relatos violentos sido induzida pelo tipo de abordagem que os alunos de Teatro fizeram aos entrevistados, solicitando-lhes que contassem um momento "marcante" de suas vidas? Ou seja, a ideia de que deveriam falar de algo "marcante" levouos a selecionar histórias que causassem emoções fortes? Ou, por outra, sabendo que se tratava de uma pesquisa para a aula de Teatro da escola, teriam os entrevistados buscado um enquadramento dramático de suas vidas na seleção da história que forneceriam? Isto é, teriam eles sido influenciados pela noção de conflito subjacente ao estilo dramático?

Seria difícil encontrar uma resposta definitiva para a instigante questão com a qual nos deparamos e nenhuma das duas hipóteses isoladas parece dar conta de esclarecer nosso achado. Ambas parecem pertinentes e, afinal, vistas de forma conjugada, compõem um quadro explicativo possível. De todo modo, sobre as duas hipóteses, há uma observação que deve ser feita: elas relacionam dois elementos fundamentais em nosso projeto teatral, quais sejam o documental e o ficcional. Eles estão presentes desde o início de nosso processo - já se evidenciavam na discussão inspiradora sobre o filme de Coutinho e não cessariam de aparecer nas etapas subseqüentes, como veremos mais adiante.

Antes, porém, vale notar que o tema da violência entre a ficção e a realidade não é raro aparecer em aulas de Teatro com diferentes turmas do CApUERJ. Por exemplo, recentemente, em turmas de quarto e quinto ano do Ensino Fundamental, trabalhei um jogo cênico em que os alunos eram orientados a fazer uma ação com uma garrafa de plástico como se ela fosse qualquer outro objeto que concebessem. Foi bastante frequente a transformação da garrafa em armas imaginárias (revólveres, escopetas, facas, espadas). Pedi para que os alunos refletissem sobre o fato e, assim, eles apontaram fundamentalmente dois motivos para explicá-lo: 1) a intensa exposição a filmes ou games violentos; 2) a influência da própria realidade em que vivem, ou seja, a violência anunciada nos noticiários, o contato cotidiano com relatos de violência envolvendo pessoas próximas e, finalmente, o testemunho ou a vivência concreta de episódios violentos. Essas foram, portanto, as respostas elencadas pelas crianças, entre a violência no âmbito da ficção e o mundo real violento.

No processo de trabalho desenvolvido com os alunos de primeiro ano E.M. de 2013, também procuramos desenvolver um pensamento sobre as causas da recorrência da violência nos relatos de nossos entrevistados, resultando num texto que seria incluído no programa do espetáculo, entregue à platéia. Esse texto foi redigido por um grupo de alunos da turma que, além de atuar em cena, ficou responsável pela parte teórica de nosso trabalho. Vejamos: 
Mas qual seria o principal motivo dessa forte presença da violência? Poderia ser por causa de uma espécie de desorientação cultural, onde não são reforçados os valores éticos como o bem comum, amor ao próximo, a justiça, honestidade, dignidade e etc? Seria a própria natureza humana que faz com que sentimentos como a inveja, ganância, desejo pela vantagem individual, vaidade e ódio dominem as ações de certas pessoas?

Ou a grande tensão presente nas relações humanas e motivos banais que podem fazer com que uma pessoa perca sua cabeça e cometa atos violentos e justiças com as próprias mãos? Ou também uma atual violência como forma de espetáculo, show, feita a partir de filmes e programas de TV, que fazem tal problema parecer algo muito normal? Poderia ser também a impunidade que dá a impressão de que as pessoas podem fazer o que bem desejarem que não serão punidas por seus erros ou crimes?

Acontece que não seria possível encontrar uma única resposta para esse questionamento porque a violência é algo muito mais complexo, logo esse conjunto de fatores pode servir de explicação para o problema, pois o ser humano, influenciado pelas questões citadas anteriormente, acaba agindo de maneira violenta e inconsequente em diversas situações do cotidiano.

Na reflexão dos alunos, é possível perceber, portanto, uma forte preocupação acerca da origem do gesto humano violento. Seria ele decorrência de uma falha em nossa formação enquanto seres humanos ou seria inerente à nossa natureza? A espetacularização da violência e a certeza da impunidade surgem também, no discurso, como elementos que possivelmente impulsionam ou reforçam a prática violenta. $E$ a conclusão é de que o tema, complexo e multifatorial, segue tendo grande relevância por nos afetar de modo frequente.
No texto escrito pelos alunos, percebemos parte das ideias desenvolvidas mais acima e também novos questionamentos, o que se deu num importante exercício de pensamento, fruto de um processo de trabalho que se caracterizou não só pelo fazer cênico, mas pela conjugação do fazer e do refletir, suscitando uma postura ativa dos participantes em cada uma das etapas de criação de nosso espetáculo: tanto na primeira, em que fizeram a coleta de relatos junto a diferentes pessoas da escola e pensaram sobre os achados feitos, como na segunda, em que se debruçariam sobre esses relatos no intuito de torná-los textos de cena.

\section{SEgunda ETAPA: A CONSTRUÇÃo DO ESPE- TÁCULO}

O tema principal de nosso espetáculo estava definido: violência. Isso daria unidade à nossa obra e orientaria várias de nossas escolhas. As histórias de nossos entrevistados teceriam nosso texto. Para tanto, cuidamos logo de registrá-las em vídeo. As gravações foram feitas no auditório da escola, onde o espetáculo seria apresentado meses mais tarde. A escolha parecia adequada, inspirando-se no próprio filme "Jogo de cena", em que as entrevistas acontecem no palco de uma sala teatral à italiana.

Uma vez gravados os relatos das histórias por seus verdadeiros "autores", os alunos distribuíram-se em grupos e cuidaram de transformá-los em texto. Pedi para que os transcrevessem e, nos casos longos demais, selecionassem as partes sobre as quais desejassem trabalhar. Em seguida, pedi para que decorassem esses textos, sem modificações, dividindo-o como quisessem entre os integrantes de cada grupo.

Lançamo-nos, então, aos ensaios cênicos propriamente ditos; começamos a experimentar diferentes formas de encenar os relatos. Inspirados pelo filme de 
Coutinho, inicialmente perseguimos a ideia de confundir nossos espectadores sobre quem seria o verdadeiro dono da história que estava sendo contada. Pretendíamos, ingenuamente, que nossa plateia pudesse ter a ilusão de que aquelas histórias haviam realmente ocorrido com os alunos que interpretavam seus relatos. Mas logo nos fomos defrontando com dificuldades que nos dissuadiriam dessa ideia: por exemplo, o fato da idade e outras características dos alunos não serem compatíveis com os acontecimentos de alguns dos relatos. Aos poucos, essa primeira concepção começou a parecer superficial também do ponto de vista artístico. A tentativa de hiper naturalidade, difićlima de ser alcançada, resultava, em nosso caso, numa cena fraca e desinteressante.

Além disso, havia uma diferença fundamental entre nossa proposta de trabalho e a do filme que nos inspirara: o suporte sobre o qual se daria nossa arte. Os alunos não seriam filmados, como as atrizes de Coutinho; eles enunciariam os relatos de forma presencial, numa apresentação teatral. Ora, qual a especificidade do teatro? De acordo com Aristóteles, "não é ofício do poeta narrar o que aconteceu; é, sim, de representar o que poderia acontecer (...)" (ARISTÓTELES, 1993, p.53; grifos meus). E ainda: "Com efeito, não diferem o historiador e o poeta por escreverem verso ou prosa (...) - diferem, sim, em que diz um as coisas que sucederam, e outro as que poderiam suceder" (IBIDEM, p.53; grifos meus).

Com essas palavras, Aristóteles busca explicar o conceito de verossimiIhança e, ao mesmo tempo, fornece argumentos para a libertação do teatro do domínio absoluto de qualquer realismo que não seja necessário. Ao estabelecer limites entre o trabalho documental (do historiador) e o ficcional (do poeta dramático), o filósofo grego abre diferentes possibilidades para a arte teatral. Ainda que insistíssemos na encenação dos relatos das histórias, tal como ocorria no filme de Coutinho, e não nos desviássemos para a apresentação dramática dos acontecimentos relatados, procedimento mais convencional no teatro, precisávamos repensar a maneira como faríamos isso. Levei essa reflexão aos alunos e sugeri que, para encontrar a força de nossa cena, teríamos que buscar algo novo, para além do que tínhamos buscado até então. A compreensão teórica disso apareceria no texto do programa escrito pelos alunos no final do processo:

Quanto à encenação, começamos os ensaios buscando atuar do modo mais verossímil possível, ou seja, tentando convencer o público de que a história ocorreu realmente com o próprio ator intérprete do respectivo conto. No entanto, com o tempo, fomos percebendo que isso não resultava teatral. Segundo Aristóteles, os trabaIhos do historiador e do poeta são diferentes porque o primeiro narra o que realmente aconteceu e o segundo narra as coisas como poderiam ter acontecido. Algo semelhante passou a valer para nós: não se tratava de alterar as histórias contadas, mas de interpretar o momento da contação não como realmente aconteceu, com a emoção cotidiana e contida que os personagens reais empregaram, mas com a emoção que poderia ter acontecido, porque o teor dramático da história exigia isso!

Essa compreensão deu-se gradativamente. Numa fase bastante inicial de nossos trabalhos, antes mesmo de começarmos a construção do espetáculo, enquanto ainda experimentávamos pequenos improvisos em sala de aula, já houvera descobertas que contribuíam embrionariamente para esse entendimento. Vejamos um exemplo: realizamos certa vez um exercício em que os alunos, reunidos em trios, selecionavam a história de um deles para narrar em cena; os três iam para a cena e, sucessivamente ou intercaladamente, como preferissem, contavam a 
e-Mosaicos - Revista Multidisciplinar de Ensino, Pesquisa, Extensão e Cultura do Instituto de Aplicação Fernando Rodrigues da Silveira (CAp-UERJ)

mesma história do início ao fim; ao final, a plateia deveria descobrir qual dos três alunos era o verdadeiro autor da história.

Um dos grupos, composto por duas meninas e um menino, contou uma história que ocorria numa sapataria. A personagem que falava em primeira pessoa desejava comprar um sapato feminino, de salto alto, e experimentava-o. Desde logo, portanto, percebemos que a história não podia pertencer ao menino, já que se tratava de um sapato feminino. Entretanto, 0 que nos surpreendeu foi que, sob o ponto de vista teatral, o seu relato revelou-se o mais interessante, mesmo que tivéssemos certeza de que ele não tinha vivido realmente aqueles acontecimentos específicos. Isso porque a arte teatral difere da arte documental. Há, na cena teatral, algo além da realidade, a que podemos chamar, de modo geral, de teatralidade.

Em nosso processo, a descoberta da necessidade da teatralidade foi-se dando em meio ao próprio fazer, o qual, aos poucos, mostrava-nos caminhos e levavanos, inclusive, a reavaliar a maneira como os próprios entrevistados faziam seus relatos. Seriam eles mais convincentes que nós ao contarem suas histórias pessoais? Ou, ainda, mesmo que o fossem, seriam eles mais interessantes ao fazê-lo? Por exemplo, ao falar de um episódio que causava temor, percebemos que um dos entrevistados não acessava a emoção correspondente, mas, pelo contrário, mantinha um tom quase monocórdio. No geral, os entrevistados tendiam a distanciar-se dos acontecimentos para narrá-los ou a esmaecer a emoção que haviam realmente sentido no passado, no momento mesmo em que estiveram vivendo as histórias contadas.

Ora, a atitude dos entrevistados era exatamente oposta à que comumente solicitamos aos atores: pedimos-lhes que busquem conectar-se com a emoção exigida pelas palavras que proferem; solicitamos-lhes que imaginem estar revivendo o episódio que apresentam ao público; sugerimos-lhes que acessem sua memória afetiva. Mais uma vez, nossa prática trazia à tona a discussão acerca do real e do ficcional, remetendo às próprias questões levantadas pelo filme "Jogo de cena". Ao seguir os passos de construção da obra que nos servira de inspiração, encontrávamos enfim questionamentos muito semelhantes àqueles por ela suscitados.

A partir do momento em que percebemos isso definitivamente, mudamos nossos rumos. Tínhamos que buscar a teatralidade! Pedi, entretanto, que os alunos não alterassem as palavras dos textos transcritos, delimitando com clareza um campo de criação. Manter o texto original nos daria um parâmetro de comparação muito sólido entre a cena teatral e os relatos de nossos entrevistados gravados em vídeo. Além disso, os alunos ver-se-iam forçados a imaginar formas de teatralização para além da forma dramática clássica, baseada no diálogo e na apresentação das ações dos personagens. Fora esses recursos, eles poderiam criar o que quisessem no tocante à maneira de dizer e apresentar o texto: relato, jogral, expressão corporal, repetições e até mesmo curtas dramatizações, desde que não se instaurasse o diálogo.

A pesquisa não era óbvia nem fácil. Os resultados não vieram imediatamente e foi necessário, mais do que nunca, trabaIhar e retrabalhar nosso fazer nos ensaios cênicos. Afinal, alguns resultados foram alcançados, como pudemos perceber em algumas das cenas criadas pelos alunos. Tomemos como exemplo o relato da história da inspetora agredida verbalmente por um aluno na porta da enfermaria da escola. Na cena, que intitulamos "O desbocado", três alunas-atrizes optaram por investir cada uma em uma emoção diferente. Dividiram o texto em três partes sequenciais e, orientadas pelos sentimentos identificados no relato da inspetora, escolheram três a serem explorados intensamente: 
primeiro, a angústia, em seguida a raiva/revolta e, enfim, a tristeza/choro (fig.1). E, ao final da cena, repetiam algumas vezes a mesma frase, cada uma com sua emoção: "Isso foi demais para mim!" Separando os sentimentos, que originalmente apareciam misturados, evidenciavam e reforçavam cada um deles.

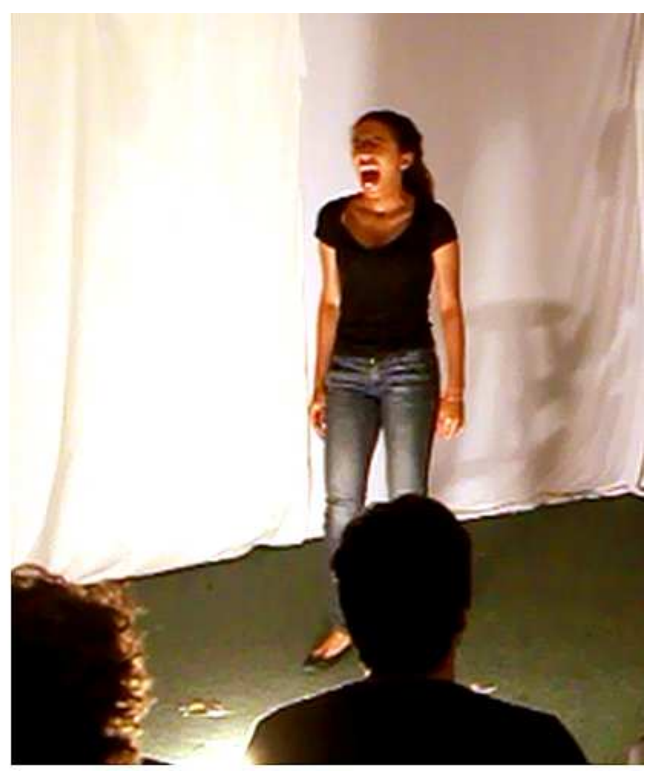

Figura 1 - Em "O desbocado", a aluna-atriz Valentina Magno investiu com intensidade na emoção de raiva/revolta ao interpretar o relato fornecido por uma inspetora da escola

Vejamos também o exemplo do relato da briga envolvendo um rapaz e um grupo de adolescentes durante o carnaval, numa praia da zona sul do Rio de Janeiro, motivada pela tentativa do primeiro de roubar o gelo do isopor do segundo. $\mathrm{Na}$ cena, que intitulamos "A guerra do gelo", dois alunos contavam o episódio de maneira intercalada, imprimindo às falas uma atitude de divertimento que, no relato original, existia de maneira contida. Vejamos um trecho do relato sobre o momento em que o rapaz que tentava roubar o gelo foi agredido pelo grupo de adolescentes:
(...) a gente estava em muito maior número, umas dezesseis pessoas, quinze pessoas. A gente começou a juntar nele. Juntou todo mundo de uma vez mesmo nele, começou a dar soco... aí pegou uma garrafa de vodca que tava vazia e bateu nele. Mas, tipo, ele, ele apanhou muito, mas ele não parava de bater também, sabe? Aí ele apanhou muito, muito. E aí chegou uns caras e separaram, sabe? Os policiais pegaram ele e levaram. E a gente saiu, sabe, de boa.

Os alunos-atores optaram por rir muito da situação, aumentando, com isso, o contraste entre a violência contida no que diziam e o prazer leviano ou cruel que sentiam os personagens que interpretavam. No momento em que falavam do ataque com a garrafa de vodca, os alunos chegavam a gargalhar. Em vez de esconder ou conter o prazer, colocavam sobre ele uma lente de aumento para que a platéia o enxergasse e o criticasse. Ficava nítida a incongruência, sob o ponto de vista moral e ético, entre o que era dito e a emoção empregada.

Por fim, um último exemplo: a cena sobre o relato da família que, em viagem de carro numa estrada, é perseguida por ladrões, intitulada "Faroeste caboclo". Nela, três alunos-atores trabalharam com três intensidades de emoção. O primeiro a falar procurava ser pouco expressivo e econômico corporalmente; o segundo buscava algum nervosismo em sua fala e maior liberdade corporal; o terceiro intensificava a emoção, além de engajar o corpo de modo mais expansivo. Depois, o segundo retomava a fala deixando-se contaminar pela intensidade do terceiro e, no momento de maior tensão do relato, quando a família no carro, na iminência de ser alcançada pelos bandidos, gritava para o condutor do veículo "Acelera, acelera, acelera!!!", os três alunos o faziam juntos. Em seguida, o primeiro aluno-ator finalizava a história, com um tom mais calmo: "E aí a gente conseguiu fugir e depois foi na 
delegacia, fazer um B.O. e tal. E, assim, na hora, a gente nem sente o nervosismo. É mais depois que avalia".

Ao trabalharem com a gradação da emoção, os alunos-atores deixavam exposta à plateia a clássica ordenação da narrativa dramática, iniciando com a apresentação do conflito, chegando ao clímax, momento de maior tensão, e terminando no desfecho. Tratava-se de um verdadeiro estudo sobre como contar a história, originalmente narrada de maneira quase monocórdia, sem nuances.

Poderíamos reutilizar a fala final da cena, citada acima, para fazer uma analogia com o que, afinal, procuramos fazer com os relatos de nossos entrevistados: se, ao nos apresentarem suas histórias, em sua atitude mais ou menos espontânea, nossos colaboradores não tinham completa consciência da emoção que expressavam ou deixavam de expressar (por exemplo, nervosismo), nós, diante do material fornecido por eles, realizávamos um trabalho de avaliação, análise e seleção. A partir daí, procurávamos exatamente investir os relatos de uma determinada intensidade de sentimentos que poderia têlos acompanhado. Ou seja, buscávamos refazer os relatos não como aconteceram de fato, mas como poderiam ter acontecido.

\section{Terceira etapa: "B.O. (Boletim de O- CORRÊNCIA)", O ESPETÁCULO}

O público entra e se acomoda. Black out. Projeção de vídeo (colagem de cenas violentas extraídas de clássicos do cinema: tiros, facadas, lutas, desastres automobilísticos). Música tensa. Tela preta. Projeção, em letras brancas, do título do espetáculo: "B.O. (Boletim de Ocorrência)". Black out novamente.

Assim começava nosso espetáculo. A colagem de cenas violentas, feita por um grupo de alunos apaixonados pela sétima arte, visava em parte prestar uma homenagem ao cinema, de onde partira a inspiração de nosso projeto, mas também introduzir o tema geral do espetáculo e, em especial, fazer referência ao tema da violência no lugar da ficção. Ao apontar para a violência no espetáculo que ali tinha início, a projeção falava também do espetáculo da violência, propagado em telas de cinema e televisão.

Após aquele momento inicial, ainda no escuro, a platéia escutava em off um trecho de Raízes do Brasil acerca do homem cordial:

Já se disse, numa expressão feliz, que a contribuição brasileira para a civilização será de cordialidade - daremos ao mundo o 'homem cordial'. (...) a hospitalidade, a generosidade, virtudes tão gabadas por estrangeiros que nos visitam, representam, com efeito, um traço definido do caráter brasileiro (...). Seria engano supor que essas virtudes possam significar 'boas maneiras', civilidade. São antes de tudo expressões legítimas de um fundo emotivo extremamente rico e transbordante (HOLANDA, 1995, p. 146-147).

Esta fala contrastava com o que 0 público tinha visto anteriormente: se a projeção do vídeo inicial impactava pela violência, o texto em off mencionava a cordialidade; se a colagem de cenas violentas remetia primordialmente ao universo norte-americano, a locução situava-nos inequivocamente no Brasil; se a referência ao cinema delimitava, sem dúvida, o campo da ficção, as palavras extraídas de Raízes do Brasil apresentavam a tentativa de interpretação da verdade acerca de nossa sociabilidade. Esse contraste anunciava, em certa medida, o entrecruzamento de idéias que o espetáculo suscitaria dali em diante: a violência entre a ficção e o real; a violência no lugar da suposta cordialidade brasileira.

A leitura da cordialidade do povo brasileiro teria, então, de se diferenciar do 
senso comum, não significando simplesmente "hospitalidade" ou "generosidade". Queríamos mostrar em nossas histórias o fundo emotivo nelas contido. $E$, em seu conjunto, marcado pela recorrência da violência, elas formariam, para a platéia, uma imagem contraditória com o "mito fundador de nossa nação", baseado na crença generalizada de que o povo brasileiro é, antes de tudo, "um povo pacífico, ordeiro, generoso, alegre e sensual (...)" (CHAUI, 2001, p.8).

Após o início acima descrito, nosso espetáculo organizou-se sobre a alternância entre as cenas teatrais criadas pelos alunos e os vídeos gravados com nossos entrevistados. Ou seja, apareceriam de modo intercalado os verdadeiros "autores" das histórias e os alunos-atores. Essa forma fragmentada, não-linear e de ordenação não-evidente (não apresentávamos de forma contígua a mesma história, mas de modo aparentemente aleatório), tinha, mais uma vez, inspiração na montagem do filme "Jogo de cena".

Quando os vídeos eram exibidos, estabelecia-se uma espécie de espelhamento com a platéia. Os entrevistados tinham sido enquadrados com a arquibancada da plateia vazia ao fundo e os vídeos eram projetados na direção oposta durante o espetáculo, isto é, sobre a tela que se estendia no fundo do palco. Fazíamos alusão à ideia de que, se nossas histórias haviam nascido no espaço de realidade dos espectadores, elas caminharam, em nosso trabalho de encenação, para o espaço ficcional da cena, ou seja, no sentido do real para o ficcional.

Vale notar que, para efeito de contraste, resgatamos e acrescentamos às sete histórias com traços violentos uma única que não trazia essa característica, mas, ao contrário, versava sobre o amor, mais precisamente o amor à primeira vista. Com o relato de um rapaz que se apaixona por uma desconhecida, na biblioteca da faculdade, apresentávamos, afinal, oito histórias, oito personagens e seus oito "autores" (os entrevistados). O conto do amor à primeira vista começava e terminava o espetáculo, primeiro com a cena criada por duas alunas-atrizes e, no final, com a projeção do vídeo do professor que nos fornecera a história. Em meio à aridez do tema principal, esses momentos representavam um sopro de esperança e de suavidade.

Nomeamos as cenas criadas pelos alunos com títulos que eram projetados, no escuro, em letras brancas sobre fundo preto, imediatamente antes da apresentação de cada uma delas: "Peça do destino", "Metrópolis, "Faroeste caboclo", "Ponto de bala", "Guerra do gelo", "Profissão de risco", "Desbocado" e "Acerto de contas". A transição abrupta entre uma cena e outra, marcada sempre por um black-out, acabava por remeter, afinal, à secura de um boletim de ocorrência ou à própria brutalidade de tudo o que é violento.

Além disso, a inexistência de encadeamento dramático, numa montagem baseada no corte, também situava o espetáculo no rol dos experimentos cênicos contemporâneos. Aliás, toda a investigação habitava esse espaço, uma vez que o fenômeno artístico teatral debruçava-se sobre si mesmo, fazendo indagações sobre o próprio modo de se interpretar um texto, adentrando o mundo do épico, abrindo mão do diálogo, deixando à mostra os procedimentos utilizados, desnudando-se dos mecanismos de construção da ilusão.

Essa compreensão viria claramente, por parte dos alunos, no texto do programa:

Trabalhando com a falta de linearidade e a fragmentação que marcam tanto o cinema quanto o teatro contemporâneos, em B.O. (Boletim de Ocorrência), procuramos levantar algumas indagações: o grau de veracidade de uma história é maior quando narrado pela pessoa que realmente a vivenciou ou pelo ator que a 
interpreta? A ficção consegue ser mais crível e, portanto, mais persuasiva que a própria realidade? 0 que esperamos ver quando vamos ao teatro? Quantos graus de representação são possíveis desde a realidade até o teatro mais, digamos, "teatral"?

Eis um bom resumo de nossas discussões ao longo do processo de encenação. Ao mencionar a problemática dos diversos graus de representação que compõem a realidade e a ficção, as palavras acima apontam o eixo em torno do qual nosso projeto e sua análise procuraram desenvolver-se. Isso sob duas vertentes: a da maneira de encenar/interpretar e a da abordagem da temática da violência.

Afinal, nosso projeto, em seu conjunto, atravessou diversas camadas de realidade: 1) a dos verdadeiros "autores" dos relatos, que, além de possivelmente terem sido influenciados por nossa abordagem ao escolherem a história a ser contada, proferiram-na de modo mais ou menos espontâneo, já que sob a mira de nossa câmera; 2) a do tratamento que demos ao material que recolhemos, buscando inicialmente a criação de uma ilusão de realidade e, por fim, rejeitando-a e tentando encontrar a própria teatralidade; 3 ) e, finalmente, a da recepção do espetáculo pela platéia. Quantas interpretações do que foi apresentado? Quantas relações com as vivências concretas de cada espectador? No tocante ao tema da violência, que questionamentos?

\section{ENTRE A REALIDADE E A FICÇÃO}

Em suma, poderíamos dizer que, em nossa experiência teatral, a questão do real e do ficcional esteve presente em todas as etapas e perpassou todas as discussões: seja no tocante às investigações acerca das maneiras de se interpretar um texto no teatro, seja no que se refere ao tema da violência e à busca dos motivos que o levaram a se colocar de modo recorrente entre nossos entrevistados.

Escritas com o distanciamento de três anos da experiência vivida, as reflexões aqui expostas parecem surpreendentemente atuais. Importam para a arte teatral contemporânea e para o mundo contemporâneo em geral que, ao relativizar o valor e a própria existência de uma verdade por trás dos fatos, confere às nossas performances de representação um papel, muitas vezes, determinante. Importam, ainda, se quisermos ampliar bastante nossos horizontes, para o pensamento sobre a própria sociabilidade brasileira, contribuindo para a discussão do lugar da violência entre nós. Contrapondo-se a uma ideia vulgarizada de cordialidade brasileira, nosso espetáculo trouxe à tona uma imagem de Brasil violento, talvez como sintoma de uma mudança na maneira de nos percebermos.

$\mathrm{Na}$ análise de "B.O. (Boletim de Ocorrência)", poderíamos ir além do espetáculo da violência (numa recepção passiva do violento enquanto ficção) e dissecar a violência apresentada no espetáculo (numa análise da violência como realidade). Para tanto, seria necessário pensar sobre as diversas camadas de violência presentes em nossa estrutura social. Teríamos, assim, um tema para novas investigações num campo que extrapola o das artes teatrais. Infelizmente, as notícias que nos chegam a cada dia sobre nosso país fazem imaginar que, em curto prazo, nossa realidade não cessará de fornecer material para pensarmos sobre o assunto e para possivelmente dialogar com a ficção.

\section{REFERÊNCIAS BIBLIOGRÁFICAS}

ARISTÓTELES. Poética. São Paulo: Ars Poetica, 1993. 
e-Mosaicos - Revista Multidisciplinar de Ensino, Pesquisa, Extensão e Cultura do Instituto de Aplicação Fernando Rodrigues da Silveira (CAp-UERJ)

CHAUÍ, Marilena. Brasil - Mito fundador e sociedade autoritária. São Paulo: Fundação Perseu Abramo, 2001.

HOLANDA, Sérgio Buarque de. Raízes do Brasil. São Paulo: Companhia das Letras, 1995.

STANISLAVSKI, Constantin. A preparação do ator. Rio de Janeiro: Civilização Brasileira, 1995. 